\title{
Physical Properties of Some Zinc Oxide-Eugenol Cements
}

\author{
J. RUSSELL ANDERSON, JR., and GEORGE E. MYERS \\ The University of Michigan School of Dentisiry, Ann Arbor, Michigan
}

\section{SYNOPSIS IN INTERLINGUA}

Proprietates Physic de Certe Cementos a Oxydo de Zinc e Eugenol.-Le hic-reporate studio esseva concernite con le consistentia, le fortia compressive, le tempores de travalio e de prisa, le spissitate de pellicula, e le duressa del materiales studiate. Lor numero esseva 6. Le valores pro le consistentia variava inter 35 e $60 \mathrm{~mm}$. Le fortias compressive variava ab 6,4 ad $219 \mathrm{~kg} / \mathrm{cm}^{2}$. Le tempore de travalio esseva inter 3 e 21 minutas, e le tempore de prisa final esseva inter 5,5 e 20 minutas additional. Omne le cementos produceva un spissitate de pellicula de minus que $0,04 \mathrm{~mm}$. Le valores del duressa post 24 horas variava inter 0,05 e $1,1 \mathrm{~mm}$ de penetration.

Zinc oxide-eugenol mixtures long have been used in dentistry, first as cements and later as impression materials. The basic physical properties both of the cements and of the impression pastes are similar. Early investigations of the zinc oxide-eugenol mixtures were concerned mainly with the desirable formulation of ingredients and the setting properties of the mixtures. Wallace and Hansen, ${ }^{1}$ Molnar and Skinner, ${ }^{2}$ Harvey and Petch, ${ }^{3}$ and Paffenbarger and $\mathrm{Caul}_{,}{ }^{4}$ were among the investigators to describe desirable compositions for zinc oxide-eugenol mixtures. Numerous authors ${ }^{5-15}$ studied the effect of additives on zinc oxide-eugenol mixtures to reduce the setting times or to improve one or more of the physical properties of the cement. The nature of the setting reaction of zinc oxide-eugenol mixtures has been described by Copeland and co-workers $^{16}$ and Smith. ${ }^{17}$ More recent studies published on the physical properties of the zinc oxide-eugenol cements include those of Norman and co-workers, ${ }^{18}$ Swartz and others, ${ }^{19}$ and Oldham, Swartz, and Phillips. ${ }^{20}$ The latter two studies include investigation of the physical properties of some commercially available zinc oxide-eugenol cements. The properties of the zinc oxideeugenol impression pastes have been reported by Skinner, Cooper, and Ziehm, ${ }^{21}$ Asgarzadeh and Peyton, ${ }^{22}$ Vieira, ${ }^{23}$ Clark and Phillips, ${ }^{24}$ and Myers and Peyton. ${ }^{25}$ The response of the dental tissues to zinc oxide-

Based on a thesis submitted by the senior author in partial fulfillment of the requirements for the M.S. degree at the University of Michigan, Ann Arbor, Mich.

Received for publication May 21, 1965. eugenol mixtures has been discussed by many authors, including Dubner and Stanley, ${ }^{26}$ James and Schour, ${ }^{27}$ Manley, ${ }^{28}$ and Mjör. ${ }^{29}$

The zinc oxide-eugenol cements have been used mainly as temporary restorations during the treatment of teeth and prior to the placing of the final restoration. Recently, these cements have been used in the temporary cementation of fixed bridges and other restorations. ${ }^{30,31}$ This procedure allows a period of adjustment, during which the tissue response of both the teeth and the supporting tissues can be observed. Because of the anodyne effect of the zinc oxideeugenol cements, as compared with the irritant zinc phosphate cements, they are especially suitable in the initial placement of fixed prostheses where extensive abutment preparations have exposed large areas of dentin. In some instances where extensive fixed prostheses are placed following periodontal therapy, it has proven advantageous to continue the temporary cementation phase for a year or longer. The prosthesis can be removed from time to time, examined, and adjusted and the tissues can be checked, following which the appliance is again temporarily cemented for a further period. In this way, permanent cementation may be indefinitely postponed.

There are a number of the zinc oxideeugenol cements available. They differ in the manner in which they are packaged, prepared, and manipulated during use. The physical properties of these cements vary in relation to setting time, consistency, strength 
TABLE 1

PRODUCTS TESTED

\begin{tabular}{cll}
\hline & \multicolumn{1}{c}{ Trade Name } & \multicolumn{1}{c}{ Manufacturer } \\
\hline Product & & Interstate Dental Co., New York, N.Y. \\
A & Opotow & Kerr Manufacturing Co., Detroit, Mich. \\
B & Tempbond & T. D. Caulk Co., Milford, Del. \\
C & Temporary Cement & L. S. White Dental Mfg. Co., Philadelphia, Pa. \\
D & Z-O-E & S. S. Whalif. \\
E & Tem Pak & Westward Dental Products Co., San Francisco, Calif. \\
F & A.D.A. Formula \#2 & Quarry Inc, Ann Arbor, Mich. \\
& & \\
\hline
\end{tabular}

of the set cement, and in other ways less easily defined. These various cements lend themselves to different clinical use. The properties required when cementing a temporary aluminum crown, which is to be removed in a few days' time, are not the same as those required when an extensive fixed prosthesis is to be temporarily cemented for a period of a month or more. A cement with a short setting time, a comparatively low compressive strength, and a heavy consistency is suited to the former procedure, and a cement with a longer setting time, a light consistency, and a higher compressive strength is better for the latter operation.

Preliminary to a clinical study of the zinc oxide-eugenol cements, the present study was undertaken to determine the physical properties of six commercially available zinc oxide-eugenol cements. The physical properties investigated were consistency, working and setting time, hardness, film thickness, and compressive strength.

\section{Materials and Methods}

The cements tested are listed (Table 1). Two of these products were the paste variety supplied in collapsible metal tubes (products $A$ and $B$ ) and the other four were the powder and liquid type. Product $F$ was compounded to the formula described by Wallace and Hansen. ${ }^{1}$ This cement and product $\mathrm{E}$ are intended for use as temporary restorative materials and are not temporary cements in the true sense of the term. They were included for purposes of comparison and because they are sometimes used as temporary cements.

Mixing AND PRoportioning.-Products $A$ and $B$, the paste type of material, were proportioned according to the manufacturer's recommendations of equal lengths of base and accelerator. Product $B$ was sup- plied with a tube of modifier which, according to the manufacturer's description, reduces the hardness of the cement and facilitates the removal of the cemented prosthesis. In this study, the modifier was added in lengths of one quarter, one half, three quarters, and equal lengths as compared with the length of the base and accelerator.

For each of the powder-liquid type of temporary cement, three clinicians were asked to mix the cement as they would for cementing a fixed bridge. The amount of powder used was determined by weight. The liquid required was dispensed from a small hypodermic syringe having $0.1 \mathrm{cc}$. graduations. Note was made of the amounts of powder and liquid each clinician used and the average determined. These proportions, designated as standard mixes, are listed (Table 2) and were used in the subsequent testing procedures.

The two paste types of temporary cement were mixed for 30 seconds. The powder-liquid type of cements were mixed for 45 seconds, the extra 15 seconds being required to moisten the powder. Mixing was done on a Dixon waxed cement pad. All of the mixing and tests were carried out at a temperature of $75 \pm 2^{\circ} \mathrm{F}$. and a relative humidity of $57 \pm 2$ per cent.

Consistency.-The consistency of the cements was determined using the modified slump test as described in A.D.A. Specification No. 8 for the zinc phosphate cements. ${ }^{32}$ A measured amount of freshly mixed cement $(0.5 \mathrm{ml}$.) was placed between glass plates, and a standard weight of $120 \mathrm{Gm}$. was applied to the cement 3 minutes after the start of mixing. Ten minutes after the beginning of mixing, the $120-\mathrm{Gm}$. weight was removed and the maximum and minimum diameters of the disk were measured and the average value determined and recorded. Three de- 
TABLE 2

Proportions of MiXes and Consistency Values

\begin{tabular}{clc}
\hline Product & \multicolumn{1}{c}{ Proportion } & $\begin{array}{c}\text { Average Ring } \\
\text { Diameter (mm.) }\end{array}$ \\
\hline A & Equal lengths base and accelerator* & 35 \\
B & Equal lengths base and accelerator* & 44 \\
& Equal lengths base and accelerator plus $\frac{1}{4}$ length modifier & 44 \\
& Equal lengths base and accelerator plus $\frac{1}{2}$ length modifier & 44 \\
& Equal length base and accelerator plus $\frac{3}{4}$ length modifier & 43 \\
C & Equal length base, accelerator, and modifier & 44 \\
D & 1.5 Gm. powder to 0.5 ml. liquid* & 60 \\
E & $0.7 \mathrm{Gm}$. powder to $0.5 \mathrm{ml}$. liquid* & 49 \\
$\mathrm{~F}$ & $0.6 \mathrm{Gm}$. powder to $0.5 \mathrm{ml}$. liquid* & 45 \\
& $1.1 \mathrm{Gm}$. powder to $0.5 \mathrm{ml}$. liquid* & 49 \\
\hline
\end{tabular}

* Standard mixes.

terminations were made for each product and averaged to give the consistency value.

INITIAL AND FINAI SET.-The initial set or working time was determined using a Vicat penetrometer with a $3-\mathrm{mm}$. diameter needle and a total load of $300 \mathrm{Gm}$. A specimen of the standard cement mix was placed in a metal ring, $16 \mathrm{~mm}$. in diameter, and 8 $\mathrm{mm}$. deep. The needle was applied to the surface of the specimen for 10 seconds every 30 seconds, beginning 2 minutes after the start of the mix, and the depth of penetration was noted. The initial set is the time at which the needle no longer completely penetrated the specimen. The average of three samples run for each cement is reported as the initial setting time.

The final setting time was determined with a 1-lb. Gilmore needle. A metal mold, $10 \mathrm{~mm}$. in diameter and $5 \mathrm{~mm}$. deep, was filled with a fresh mixture of the cement. Two minutes after the start of mixing, the Gilmore needle was lowered vertically until the surface of the cement was touched. The needle was left in contact with the cement surface for 10 seconds, and the procedure was repeated at 30 -second intervals. When three indentations of a similar depth were obtained, the time at which the first of the three was made was taken as the final setting time. Three samples were tested for each cement, and an average of the three is reported.

FILM THICKNESS.--The film thickness was determined using a modification of the test described in the A.D.A. Specification No. 8 for the zinc phosphate cements. ${ }^{32}$ A portion of a standard cement mixture was placed between two flat glass plates and, 2 minutes (instead of 3 minutes as stated in A.D.A. Specification No. 8) after the start of mixing, a load of $15 \mathrm{~kg}$. was applied to the top of the plates containing the cement. Ten minutes after mixing was started, the thickness of the two plates with the cement film between them was determined with the aid of a micrometer. The difference in the thickness of the plates with and without the cement film was considered to be the film thickness. An average of three tests for each cement is reported to the nearest $5 \mu$.

HARDNESS. - The hardness of the set cements was tested with a Krebs penetrometer fitted with an A.S.T.M. D-5 needle and a total load of $100 \mathrm{Gm}$. Specimens of the cements tested were placed in metal rings $16 \mathrm{~mm}$. in diameter and $8 \mathrm{~mm}$. deep. The degree of penetration of the penetrometer needle was recorded at five time intervals as follows: at the time of the final set of the cement and at 1 hour, 3 hours, 8 hours, and 24 hours after the beginning of mixing. Three samples of each cement were tested and the average value is reported.

COMPRESSIVE STRENGTH.-The compressive strength was determined using a modification of the test described in A.D.A. Specification No. 8 for the zinc phosphate cements. $^{32}$ A lubricated cylindrical mold $12 \mathrm{~mm}$. high and $6 \mathrm{~mm}$. in diameter was placed on a flat stainless steel plate and slightly overfilled with a standard mix of cement. A second flat plate was pressed on top of the mold with the aid of a "C" clamp to remove the excess cement. The mold containing the cement was left in the constant 
TABLE 3

INitial and Final Setting Times

\begin{tabular}{|c|c|c|c|}
\hline Product & Proportion & $\begin{array}{l}\text { Working Time } \\
\quad \text { (min.) }\end{array}$ & $\begin{array}{l}\text { Setting Time } \\
\text { (min.) }\end{array}$ \\
\hline A & Standard mix & 3 & 7 \\
\hline \multirow[t]{5}{*}{$\mathrm{B}$} & Equal lengths base and accelerator & 4 & 5.5 \\
\hline & Equal lengths base and accelerator plus $\frac{1}{4}$ length modifier & 4 & 6 \\
\hline & Equal lengths base and accelerator plus $\frac{1}{2}$ length modifier & 3.5 & 5.5 \\
\hline & Equal lengths base and accelerator plus $\frac{3}{4}$ length modifier & 3.5 & 6.5 \\
\hline & Equal lengths base, accelerator and modifier & 3 & 6.5 \\
\hline $\mathrm{C}$ & Standard mix & 4 & 5.5 \\
\hline $\mathrm{D}$ & Standard mix & 7.5 & 15 \\
\hline $\mathrm{E}$ & Standard mix & 20 & $20^{*}$ \\
\hline $\bar{F}$ & Standard mix & 21 & $20^{*}$ \\
\hline
\end{tabular}

* These products had a setting time longer than 1 hour.

temperature $\left(75 \pm 2^{\circ} \mathrm{F}\right.$.) and constant humidity $(57 \pm 2$ per cent) chamber for 24 hours. The cement mold was not immersed in water as is stated in A.D.A. Specification No. 8 , because it was thought that the marginal leakage and diffusion in a clinically well-fitting casting, as well as in the compressive strength mold, would be negligible in the relation to the setting times and compressive strength in the internal portion of the set cement. Twenty-four hours after the beginning of mixing, the ends of the specimens were planed flat with a razor blade, and the specimens were removed from the mold. The specimens were examined and rejected if any voids were found. The specimens were immediately crushed in a Riehle compression testing machine. The machine was operated to apply a load of $100 \mathrm{lb}$. per minute. The values for the compressive strength are reported as the average of three or more from a lot of five specimens and were rounded off to the nearest pound per square inch. If the value for an individual specimen was more than 15 per cent below the average, it was discarded and the average of the remaining specimens was reported. If more than two of the specimens were eliminated, the test was repeated.

\section{Results}

Consistency.-The consistency values for each product tested are listed (Table 2). The consistency of all the cements fell within the range of $35 \mathrm{~mm}$. to $60 \mathrm{~mm}$. All the cements tested had consistency values that were higher than the $30 \mathrm{~mm}$. minimum re- quirement of A.D.A. Specification No. 8 for the zinc phosphate cements.

INITIAL AND FINAL SET.-The initial and final setting times for the cements tested are listed (Table 3). Products A, B, and C had initial set times in the 3 to 4 minute range. Product $\mathrm{D}$ had an intermediate working time of 7.5 minutes. Products $\mathrm{E}$ and $\mathrm{F}$ had initial setting times of 20 minutes or more.

The final setting times of the four fastest setting zinc oxide-eugenol cements range from 5.5 to 15 minutes. The two slower setting materials, which are intended primarily to be used as temporary filling materials, set in approximately one hour.

FILM THICKNEss.-The film thickness values, as determined 2 minutes after the start of mixing, are listed (Table 4). All of these values are less than the $40 \mu$ maximum set by the A.D.A. Specification No. 8 for inlay consistency zinc phosphate cement.

HARDNESS.-The results of the hardness tests, as determined by the Krebs penetrometer, are listed (Table 5). All of the temporary cements studied increased in hardness with increasing time after the final setting time. Products $B$ and $D$ attained maximum hardness the most rapidly of the cements tested. The modifier made product $B$ a quite versatile cement: with the addition of increasing amounts of modifier, the hardness could be decreased from one of the hardest cements tested to one of the softest.

COMPRESSIVE STRENGTH.-The 24-hour compressive strength values are listed (Table 6). Some materials were sufficiently hard and brittle to be crushed under load, 
TABLE 4

FILM THICkNess VALUES

\begin{tabular}{clc}
\hline \hline Product & \multicolumn{1}{c}{ Proportion } & $\begin{array}{c}\text { Film Thickness } \\
\text { (mm.) }\end{array}$ \\
\hline A & Standard mix & .005 \\
B & Equal lengths base and accelerator & .005 \\
& Equal lengths base and accelerator plus $\frac{1}{4}$ length modifier & .005 \\
& Equal lengths base and accelerator plus $\frac{1}{2}$ length modifier & .005 \\
& Equal lengths base and accelerator plus $\frac{3}{4}$ length modifier & .005 \\
C & Equal lengths base, accelerator and modifier & .005 \\
D & Standard mix & .005 \\
E & Standard mix & $<.005$ \\
F & Standard mix & .025 \\
& Standard mix & .035 \\
\hline
\end{tabular}

TABLE 5

HARDNESS VALUES

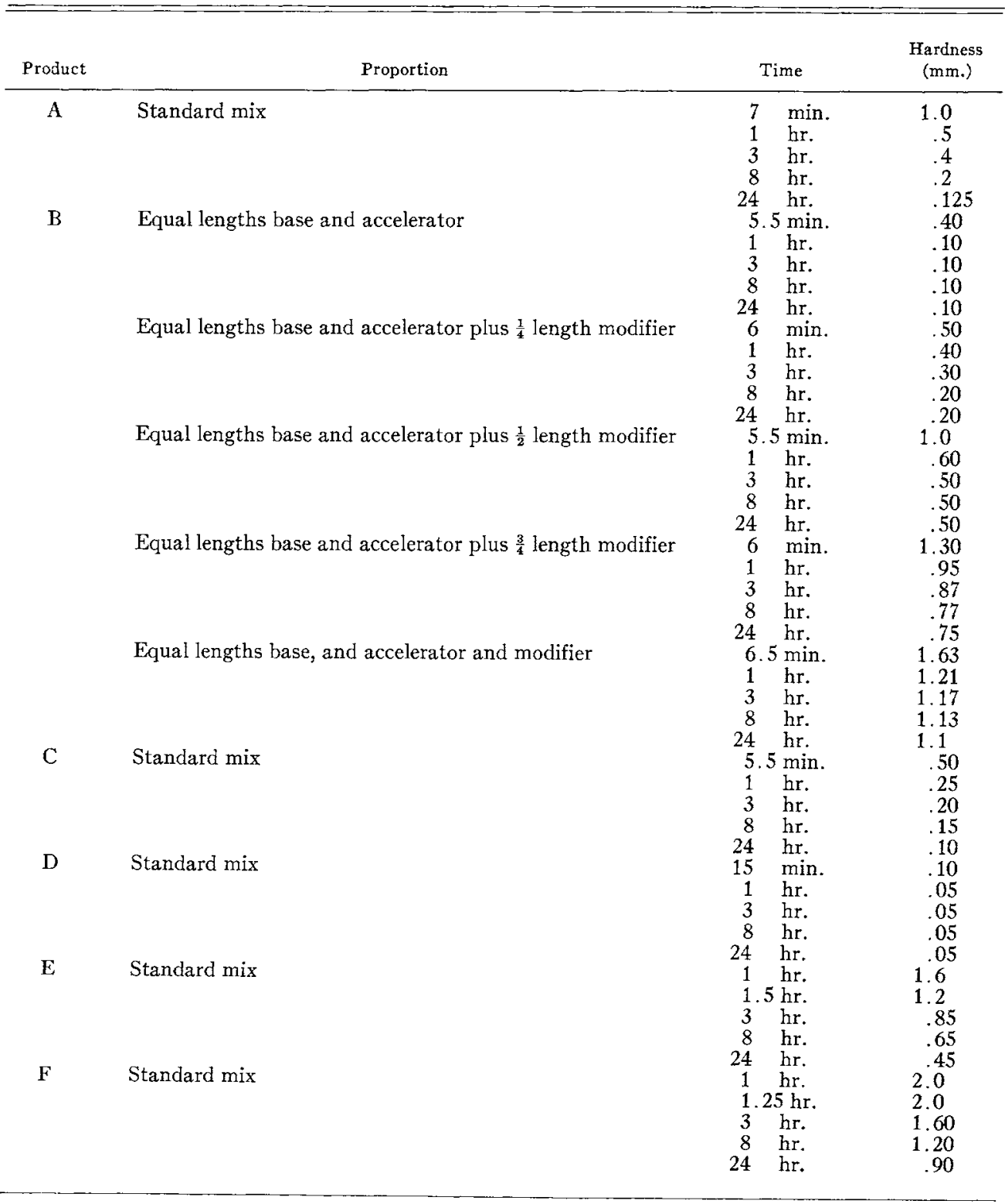


TABLE 6

TWENTY-FOUR-HOUR COMPRESSIVE STRENGTH

\begin{tabular}{clc}
\hline \hline Product & & $\begin{array}{c}\text { Compressive } \\
\text { Strength } \\
\text { (psi) }\end{array}$ \\
\hline A & Standard mix & 595 \\
B & Equal lengths base and accelerator & 1,144 \\
& Equal lengths base and accelerator plus $\frac{1}{4}$ length modifier & 538 \\
& Equal lengths base and accelerator plus $\frac{1}{2}$ length modifier & $217^{*}$ \\
& Equal lengths base and accelerator plus s length modifier & $195^{*}$ \\
C & Equal lengths base, accelerator and modifier & $144^{*}$ \\
D & Standard mix & 842 \\
E & Standard mix & 3,135 \\
F & Standard mix & $240^{*}$ \\
& Standard mix & $92^{*}$ \\
\hline
\end{tabular}

* Product did not crush; it was deformed, but there was no fracture.

but other materials were plastic and the specimen deformed under load. None of the zinc oxide-eugenol cements tested had a compressive strength that met the 12,000 psi minimum requirement set by A.D.A. Specification No. 8 for inlay consistency zinc phosphate cement.

\section{Discussion}

The consistency of the powder and liquid type of cement can be modified by varying the powder-liquid ratio and is, to some degree, under the control of the operator. The consistency of the paste type of cements is determined by the manufacturer. No attempt was made in this investigation to study the effect of varying the powder-liquid ratio on the consistency values. It is conceivable that, the thinner the consistency of the cement mix, the greater will be the flow of the cement into the irregularities on the surfaces of the tooth and the casting. This will result in greater retention of the restoration, provided, of course, that there is not a decrease in the hardness, compressive strength, or other physical properties when the powerliquid ratio is decreased. The greater the consistency of the cement, the greater is the amount of force needed to seat the casting and the more difficult it is to express the cement from under the casting. By modifying the powder-liquid ratios of the cements it is possible to alter the physical properties of the powder-liquid type of temporary cements to give the greatest convenience in handling, greatest retention, and greatest strength along with complete seating of the casting.
The dentist is interested in the working time, because this is the time during which the cement must be mixed, placed into the abutment castings and on the abutment preparations, the restorations seated, and the margins of the castings finally adapted. Three minutes would appear to be a minimum working time. A working time of less than this would probably lead to difficulties in clinical use, since mixing usually takes 30 to 45 seconds, and only a little over 2 minutes would be left to complete the other essential manipulations. For an extensive prosthesis, involving a number of abutment teeth, more time would be convenient, but probably not more than 10 minutes would ever be required. Once the working period is passed, it is advantageous to have the final set follow rapidly; this leaves less chance for the patient to break the partially set cement seal and dislodge the restoration.

The A.D.A. Specification No. 8 for the zinc phosphate cements requires a minimum setting time of 4 minutes and a maximum of 10 minutes at $37^{\circ} \mathrm{C}$. The final setting times of the four fastest setting zinc oxide-eugenol cements ranged from 5.5 to 15 minutes, which compares favorably with the zinc phosphate cements. The two slower setting materials, which are intended primarily for use as temporary filling materials, set in approximately one hour. A longer working and setting time is needed for this purpose to allow proper placement and manipulation of the cement in the cavity preparation.

The film thickness of all the cements tested was below the $40 \mu$ of the A.D.A. specification for zinc phosphate cements. 
TABLE 7

TWENTY-Four-Hour COMPRESSIVE STRENGTH AND HaRdNESS VaLUES

\begin{tabular}{|c|c|c|c|}
\hline Product & & $\begin{array}{c}\text { 24-Hour } \\
\text { Hardness } \\
\text { (mm.) }\end{array}$ & $\begin{array}{l}\text { Compressive } \\
\text { Strength } \\
\text { (psi) }\end{array}$ \\
\hline A & Standard mix & .125 & 595 \\
\hline \multirow[t]{5}{*}{$\mathrm{B}$} & Equal lengths base and accelerator & .10 & 1,144 \\
\hline & Equal lengths base and accelerator plus $\frac{1}{4}$ length modifier & .20 & 538 \\
\hline & Equal lengths base and accelerator plus $\frac{1}{2}$ length modifier & .50 & 217 \\
\hline & Equal lengths base and accelerator plus $\frac{3}{4}$ length modifier & .75 & 195 \\
\hline & Equal lengths base, accelerator and modifier & 1.10 & 144 \\
\hline $\mathrm{C}$ & Standard mix & 10 & 842 \\
\hline $\mathrm{D}$ & Standard mix & .05 & 3,135 \\
\hline $\mathrm{E}$ & Standard mix & .45 & 240 \\
\hline$\vec{F}$ & Standard mix & .90 & 92 \\
\hline
\end{tabular}

The four typical temporary cements, when mixed in the powder-liquid ratio described, had values wall below $40 \mu$. So far as film thickness is concerned, the powder-liquid ratio could be increased appreciably with possible gains in compressive strength value. The effect of increasing powder-liquid ratios on the consistency of the cement and on the ability to seat restorations easily and completely would, however, have to be kept in mind.

None of the zinc oxide-eugenol cements that was tested had a compressive strength that met the minimum requirement of $12,000 \mathrm{lb}$. psi set by A.D.A. Specification No. 8 for inlay-consistency zinc phosphate cement. Evidence is not available concerning the minimum strength required for a cement lute, however. Clinical experience with one of the products tested, which has a strength of $595 \mathrm{lb}$. psi, showed the cement to be satisfactory for a year when used for the temporary cementation of selected fixed prostheses. The strongest cement tested was about five times as strong as this material. No doubt the compressive strength could be raised by increasing the powder-liquid ratio or changing other variables affecting the cement. The desirable consistency of the cement and its value for temporarily cementing restorations might be lost, however. In the temporary cementation of restorations, the cement usually need serve only as a seal, for many restorations have considerable mechanical and frictional retention. Too strong a cement may render subsequent removal of the restoration difficult, if not impossible. For shorter periods of temporary cementation, a softer material will facilitate removal of the prosthesis prior to permanent cementation. When the prosthesis is to be left temporarily cemented for a longer time, the harder and stronger materials usually will be advantageous. The complexity of the case, the amount of retention, and the taper of the axial walls also affect the choice of a temporary cement.

There is a close correlation between the hardness and compressive strength values in each cement tested (Table 7).

This study of the physical properties of six commercially available zinc oxideeugenol cements indicates that all of them may be used for temporarily setting a restoration to an abutment tooth or cavity preparation. Because of the superior hardness, working and setting times, compressive strength, and film thickness values, products $A, B, C$, and D would seem to be superior for this purpose. Products $\mathrm{E}$ and $\mathrm{F}$, primarily because of the greater film thickness values, long setting times, and low compressive strength, are more suitable as temporary filling material, the purpose for which they are designed.

In any technic involving the temporary cementation of a restoration with the zinc oxide-eugenol cements, each clinical case must be evaluated separately, and a cement chosen with physical properties that best meet the conditions required by the case. Because of the weaker nature of the zinc oxide-eugenol cements, care must be exercised to insure that the cement seal is not broken. This breakage would be demonstrated clinically by sensitivity to thermal changes in the region around the abutment teeth, a bad taste in the patient's mouth, 
looseness of the restoration, or sensitivity to biting pressure. If this happens, the appliance must be removed immediately and the abutments checked.

\section{Summary}

This study of the physical properties of some zinc oxide-eugenol temporary cements deals with consistency, working and setting times, film thickness, hardness, and compressive strength. Six commercially available products were evaluated. All of the cements were mixed to a clinically determined "inlay setting" consistency. The consistency values for the zinc oxide-eugenol cements tested ranged from 35 to $60 \mathrm{~mm}$. These cements had working times of 3 to 21 minutes. The final setting times ranged from 5.5 minutes to over 1 hour, and the final setting times of four of the cements closely followed the end of the working period. The film thickness of all the cements was below the maximum of $40 \mu$ specified for the zinc phosphate cements when tested under the conditions described. The hardness and the strength of the set cement were closely related. The hardest cements were the strongest. The hardness and strength values of the zinc oxide-eugenol cements were far below those values for the zinc phosphate cements, however. One cement tested (product B) is supplied with a modifier with which the properties of hardness and strength can be changed to suit varying clinical requirements without a significant change in the other physical properties.

Zinc oxide-eugenol temporary cements are available with varying physical properties, and selection for clinical use can be based on the properties of the cement. Further study is needed to determine the effects of the powder-liquid ratio, temperatures, humidity, powder particle size, and manipulative variables on the physical properties of the zinc oxide-eugenol cements.

\section{References}

1. Waltace, D. A., and Hansen, H. L. Council on Dental Therapeutics. Zinc Oxide-Eugenol Cements, J. Amer. dent. Ass., 26:1536-40, 1939.

2. Molnar, E. J., and Skinner, E. W. A Study of Zinc Oxide-Rosin Cements. I. Some Variables Which Affect the Hardening Time, J. Amer. deni. Ass., 29: $744-51,1942$.
3. Harvey, W., and Рetch, N. J. Acceleration of the Setting of Zinc Oxide Cements, Brit. dent. J., 80:35$42,1946$.

4. Paffenbarger, G. C., and Caul, H. J. Dental Cements, In Proceedings, Dental Centenary Celebration, Baltimore, Maryland, March 18-20, 1940 (GEORGE M. ANDERson, editor). Baltimore, Waverly Press, 1940, p. $232-38$.

5. SLomowitz, A. Zinc Oxide-Eugenol Setting Time Accelerated, Dent. Surv., 32:901, 1956.

6. Molnar, E. J. Setting Retarders for Zinc OxideEugenol Pastes, Abstract \#M-3., Thirty-Fifth General Meeting of the I.A.D.R., 1957.

7. SMITH, D. C. A Quick Setting Zinc Oxide-Eugenol Mixture, Brit. deni. J., 108:232, 1960.

8. WEISS, M. B. Improved Zinc Oxide and Eugenol Cement, Ill. dent. J., $27: 261-71,1958$.

9. Phuldips, R. W., and Love, D. R. Effects of Certain Additive Agents on the Physical Properties of Zinc Oxide-Eugenol Mixtures, $\boldsymbol{f}$. dent. Res., 40:294-303, 1961.

10. Messing, J. J. Polystyrene-Fortified Zinc OxideEugenol Cement, Brit. dent. J., 110:95-100, 1961.

11. Roland, N., Kutscher, A. H., and Ayers, H. D. Effect of Dicalcium Phosphate on the Crushing Strength of the Zinc Oxide-Eugenol Cements, N.Y. State dent. J., 25:84-86, 1959.

12. Norman, R. D., Swartz, M. L., and Phillips, R. W. Additional Studies on the Solubility of Certain Dental Materials, J. dent. Res., 38:1028--37, 1959.

13. Brauer, G. M., and Stmon, L. Synthesis of 5-Methyl2-Propaxybenzoic Acid and Its Reaction with Zinc Oxide, J. dent. Res., 40:774-75, 1961.

14. Brauer, G. M., and Sanguermano, L. D. Studies to Reduce the Solubility of Zinc Oxide-o-Ethoxybenzoic Acid-Eugenol Cements, Abstract \#M-5, Fortieth General Meeting of the I.A.D.R., 1962.

15. Grvjan, S., and Brauer, G. M. Physical Properties of Cements, Based on Zinc Oxide, Hydrogenated Rosin, o-Ethoxybenzoic Acid and Eugenol, J. dent. Res., 43: 281-99, 1964 .

16. Copeland, H. I., Brauer, G. M., Sweeney, W. T. and ForzIAT, A. F. Setting Reaction of Zinc Oxide and Eugenol, J. Res. Nat. Burean Stand., 55:133-38, 1955.

17. Smith, D. C. The Setting of Zinc Oxide-Eugenol Mixtures, Brit. dent. J., 105:313-21, 1958.

18. Norman, R. D., Phillips, R. W., Swartz, M. L. and Frankiewicz, T. Effect of Particle Size on the Physical Properties of Zinc Oxide-Eugenol Mixtures. $J$. dent. Res., 43:252-62, 1964.

19. Swartz, M. L., Phillips, R. W., Norman, R. D., and OLDHAM, D. F. Strength, Hardness and Abrasion Characteristics of Dental Cements, J. Amer. dent. Ass., 67:367-74, 1963.

20. Oldham, D. F., Swartz, M. L., and Phillips, R. W. Retentive Properties of Dental Cements, $J$. prosth Dent., 14:760-68, 1964.

21. Skinner, W. E., CoOper, E. N., and Ziehm, H. W. Some Physical Properties of the Zinc Oxide-Eugenol Impression Pastes, J. Amer. dent. Ass., 41:449-55, 1950.

22. Asgarzadeh, K., and Peyton, F. A. Physical Properties of Corrective Impression Pastes, $J$, prosth. Dent., 4:555-67, 1956 .

23. VIEIRA, D. F. Factors Affecting the Setting of Zinc Oxide-Eugenol Impression Pastes, $J$. prosth. Dent., 9:70-79, 1959.

24. Clark, R, J., and Phillips, R. W. Flow Studies of Certain Dental Impression Materials, $J$. prosth. Dent., $7: 259-66,1957$.

25. Myers, G. F., and Peyton, F. A. Physical Properties of the Zinc Oxide-Eugenol Impression Pastes, J. dent. Res., 40:39-48, 1961.

26. Dubner, R., and Stanley, H. R. Reaction of the Human Dental Pulp to Temporary Filling Materials, Oral Surg., Oral Med. \& Oral Path., 15:1009-17, 1962. 
27. James, V. E., and Schour, I. The Effects of Cavity Preparations and Zinc Oxide and Eugenol Upon the Human Pulp, Abstract \#43, Thirty-Third General Meeting of the I.A.D.R., 1955.

28. Manley, E. B. Experimental Investigation into the Early Effects of Various Filling Materials on the Human Pulp, Proc. Roy. Soc. Med. Sect. Odont., London, 34:693-706, 1941.

29. MJör, I. A. Effect of Calcium Hydroxide, Zinc Oxide-
Eugenol and Amalgam on the Pulp, Odoni. Tidskrif., $71: 94-105,1963$.

30. Baraban, D. J. Cementation of Fixed Bridge Prosthesis with Zinc Oxide-Eugenol Cements, $J$. prosth. Dent., 8:988-91, 1958.

31. HorN, H. R. Improved Cementation, $J$. dent. Res., 39:760, 1960. Abstract.

32. American Dental Association. Specifications for Dental Materials, ed. 2. Chicago, American Dental Association, 1964, p. 104-107. 